\title{
The Burden of Agoraphobia in Worsening Quality of Life in a Community Survey in Italy
}

\author{
Antonio Preti ${ }^{1} \bowtie$, Martina Piras ${ }^{2}$, Giulia Cossu ${ }^{3}$, Elisa Pintus ${ }^{3}$, Mirra Pintus ${ }^{3}$, Goce Kalcev², Federico Cabras ${ }^{3}$, \\ Maria Francesca Moro ${ }^{4}$, Ferdinando Romano ${ }^{5}$, Matteo Balestrieri', Filippo Caraci ${ }^{7,8}$, Liliana Dell'Osso ${ }^{9}$, \\ Guido Di Sciascio ${ }^{10}$, Filippo Drago ${ }^{7}$, Maria Carolina Hardoy ${ }^{11}$, Rita Roncone ${ }^{12}$, Carlo Faravelli ${ }^{13}$, \\ Mario Musu ${ }^{3}$, Gabriele Finco ${ }^{3}$, Antonio Egidio Nardi ${ }^{14}$, and Mauro Giovanni Carta ${ }^{3}$ \\ ${ }^{1}$ Department of Neuroscience, University of Turin, Torino, Italy \\ ${ }^{2}$ PhD Programme Innovation Sciences and Technologies, University of Cagliari, Cagliari, Italy \\ ${ }^{3}$ Department of Medical Sciences and Public Health, University of Cagliari, Cagliari, Italy \\ ${ }^{4}$ Mailman School of Public Health, Columbia University, New York, USA \\ ${ }^{5}$ University of Roma La Sapienza, Roma, Italy \\ ${ }^{6}$ DAME, University of Udine, Udine, Italy \\ ${ }^{7}$ Department of Drug Sciences, University of Catania, Catania, Italy \\ ${ }^{8}$ Oasi Research Institute-IRCCS, Troina, Italy \\ 'University of Pisa, Pisa, Italy \\ ${ }^{10}$ Department of Mental Health, ASL Bari, Italy \\ ${ }^{11}$ Azienda Ospedaliera Brotzu, Cagliari, Italy \\ ${ }^{12}$ University of L'Aquila, L'Aquila, Italy \\ ${ }^{13}$ University of Florence, Florence, Italy \\ ${ }^{14}$ Federal University of Rio de Janeiro, Rio de Janeiro, Brazil
}

Objective Current nosology redefined agoraphobia as an autonomous diagnosis distinct from panic disorder. We investigated the lifetime prevalence of agoraphobia, its association with other mental disorders, and its impact on the health-related quality of life (HR-QoL).

Methods Community survey in 2,338 randomly selected adult subjects. Participants were interviewed with the Advanced Neuropsychiatric Tools and Assessment Schedule (ANTAS), administered by clinicians. The diagnoses were based on the ICD-10 criteria. The Short-Form Health Survey (SF-12) was used to quantify HR-QoL.

Results In the sample, 35 subjects met the criteria for agoraphobia (1.5\%), with greater prevalence among women (2.0\%) than men (0.9\%): odds ratio (OR) 2.23; 95\% CI: 1.0-5-2. Agoraphobia was more often seen among those with $(n=26 ; 1.1 \%)$ than without $(\mathrm{n}=9$; $0.4 \%)$ panic disorder: $\mathrm{OR}=8.3 ; 2.9-24.4$. Co-morbidity with other mental disorders was substantial. The mean score of SF-12 in people with agoraphobia was $35.2 \pm 7.8$, with similar levels of HR-QoL in people with (35.3 \pm 7.9$)$ or without ( $34.8 \pm 7.3)$ panic disorder: ANOVA: $\mathrm{F}(1 ; 33)=0.0 ; \mathrm{p}=1.00$.

Conclusion One out of seventy people may suffer from agoraphobia in their lifetime. The attributable burden in terms of HR-QoL is substantial and comparable to the one observed for chronic mental disorders such as major depression, post-traumatic stress disorder, or obsessive-compulsive disorder.

Psychiatry Investig 2021;18(4):277-283

Key Words Agoraphobia, Panic disorder, Major depressive disorder, Quality of life, Community survey, Epidemiology.

\section{INTRODUCTION}

Agoraphobia is usually defined as a state of anxiety that develops when someone is in public or crowded places and thinks $s /$ he cannot receive appropriate help when in need or cannot escape from when facing danger. Thus, people with agoraphobia strive to avoid such places or situations and tend to develop intense anxiety when forced to do it. Until Diagnostic and

Received: September 17, 2020 Revised: December 7, 2020 Accepted: December 11, 2020

$\triangle$ Correspondence: Antonio Preti, MD

Department of Neuroscience, University of Turin, Via Cherasco 15, 10126 Torino, Italy

Tel: +39-011-633-4342, E-mail: antonio.preti@unito.it

(c) This is an Open Access article distributed under the terms of the Creative Commons Attribution Non-Commercial License (https://creativecommons.org/licenses/by-nc/4.0) which permits unrestricted non-commercial use, distribution, and reproduction in any medium, provided the original work is properly cited 
Statistical Manual of mental disorders-fourth edition (DSMIV), agoraphobia was a qualifier of panic disorder. ${ }^{1}$ However, in the fifth revision of the diagnostic and statistical manual of the America Psychiatric Association, so-called DSM-5, agoraphobia was granted a formal diagnosis, which can occur independently from any other anxiety disorder. ${ }^{2}$ The current definition of agoraphobia in DSM-5 assigns a prominent role in the diagnosis to marked fear or anxiety about actual or anticipated exposure to public places or situations such as "using public transportation; being in open spaces; being in enclosed places; standing in line or being in a crowd; or being outside of the home alone in other situations" (DSM-5 code: 300.22$){ }^{2}$ Fear or anxiety must recur most of the time in at least two or more of the listed common situations. For the diagnosis, the individual must show both fears of exposure to public places and active avoidance of such situations. The fear or anxiety must not be related to a realistic threat or be explained by sociocultural context, and it should be not a consequence of substance use or withdrawal from it. Six months or more of persistent or recurrent symptomatology must be proved to make the diagnosis. On an epidemiological ground, the first age of diagnosis is relatively early: mid to late twenties. No specific "cause" has been identified for the onset of agoraphobia, but a set of risk factors tends to recur in the history of those who had received the diagnosis: besides genetic predisposition, the experience of grief or bereavement early in life, adverse or traumatic events during childhood, and parental overprotectiveness are the most often cited. A history of childhood fears or night terrors is a frequent antecedent of agoraphobia in youths and adults. ${ }^{3}$ The estimated lifetime prevalence is around $1.3 \%$ and the incidence rate is $0.9 \%$ with no difference between men and women. ${ }^{4}$ There is no established treatment for agoraphobia. For mild forms of the disorder, cognitive-behavioral therapy (CBT) is thought to be effective in alleviating symptoms and improving quality of life. ${ }^{5}$ For more severe variants, antidepressants are considered the first line of intervention. ${ }^{6}$

Agoraphobia is currently separated from panic disorder., ${ }^{4,7}$ The new category has made it possible to better define a nonnegligible share of people with agoraphobia without the panic disorder in the general population and to start defining agoraphobia as a disorder per se with a great impact on the wellbeing of the individual regardless of the presence of the concomitance or not of panic disorder. ${ }^{4}$ However, even in the DSM5 era, there are no tools validated with these criteria in literature, and many studies of validation in languages other than English still are based on interviews that adopt the DSM-IV system. ${ }^{8,9}$ The still-evolving long work of developing new diagnostic tools has not yet reached a point to allow the conduct of community surveys with the new criteria.

The definition of agoraphobia in the tenth edition of the
World Health Organization's International Classification of Diseases (ICD-10), closely resembles the definition of the disorder of the DSM-5 (ICD-10 code: F40.0), ${ }^{10}$ albeit lacking the temporal restriction of six-month continuous active symptoms. Thus, it could be helpful to re-analyze the records of databases of community studies already carried out using the ICD-10 system for the diagnosis of anxiety disorders.

This study aimed at investigating the prevalence, the demographic profile and the impact on the quality of life (QoL) of agoraphobia diagnosed according to the criteria of the ICD-10 in a large and representative sample of the general population of Italy.

\section{METHODS}

The study was approved by the by the ethical committee of the Italian National Health Institute (Rome) on August 21th, 2010 and complied with the provisions of the Declaration of Helsinki of 1995 and its revisions. ${ }^{11}$ All participants signed a written informed consent.

\section{Design, participants and procedure}

The data were drawn for the databank of a community survey. ${ }^{12}$ The study was aimed at evaluating appropriateness of drug prescription for the treatment of mental disorders in Italy, especially bipolar disorder, with a focus on antidepressants. The sample was randomly selected from the records of at least three municipalities (one urban, one suburban, and at least one rural) of six Italian regions. Those regions were selected as representative of the geographic and economic characteristics of the whole set of Italian regions. Randomization was performed in eight cells obtained after stratification of the sample by gender and age (four strata $18-24 ; 25-44 ; 45-64 ;>64$ ). Invitation in the study was by contact with the relevant general practitioners, who were initially asked to participate in the study and convey the invitation to their patients for survey collaboration. Thereafter, researchers contacted the participants by phone call and mail. Trained physicians or clinical psychologists carried out the interviews, face to face in the subjects' homes. After the explanation of the finalities of the study and the aqcquisition of a written informeed consent, interviewers asked the interviewees to show them their drug boxes, if any, and were provided with a folder to retain all of the psychotropic drug box covers. Participants were then interviewed with a semi-structured interview and were requested to fill in some self-report questionnaires, including the Health Related (HR)QoL Survey Short Form. Whenever during the interview the participants had revealed symptoms related to a mental disorder under investigation, they received an appropriate referral to primary (general practitioner) or tertiary care (local psychi- 
atric services). A detailed methodology description had ben already published earlier. ${ }^{12}$

\section{Tools}

1) The psychiatric interviews were conducted by means of Advanced Tools and Neuropsychiatric Assessment Schedule -Structured Clinical Interview (ANTAS). ${ }^{12}$ It is a semi-structured, full computerized interview derived in part from the SCID. ${ }^{13}$ ANTAS allows diagnosis of mood, anxiety and eating disorders according to DSM-IV-TR and ICD-10 with high reliability and cross-validity with SCID. ${ }^{12}$

2) The Health Related (HR)-QoL Survey Short Form (SF12) ${ }^{14}$ was used to assess perceived H-R-QoL as a measure of the impact of agoraphobia and the comorbid psychiatric conditions The SF-12 allows to measure: physical health and functionning, emotional condition, pain, general health status, vitality, social funtiionning and mental wellbeing. The HR-QoL, as measured by the SF-12, is a construct that measures the status and outcome of chronic diseases not only about the symptoms but also the relevant components of daily life. ${ }^{15}$

\section{Definitions and subgroups}

The diagnosis of major depressive disorder, post-traumatic stress disorders and anxiety disorders were defined according to ICD-10 criteria. ${ }^{10}$ All diagnoses were estimated as lifetime prevalence.

\section{Statistical analysis}

The odds ratio (OR) (univariate analysis) for ICD-10 agoraphobia diagnosis and age, gender and comorbidity with ICD10 diagnosed disorders, was calculated using as a "pivot" one group by table. The $\chi^{2}$ test was used for measuring statistical significance. Miettinen's simplified method was used for calculating Odds ratios and 95\% confidence intervals. ${ }^{16}$ The SF-12 scores by groups were compared by ANOVA one-way statistic.

The burden on the impairing HR-QoL "attributable" to agoraphobia (attributable burden) was defined as the difference between HR-QoL (mean score on the SF-12) in the sample of people without agoraphobia and HR-QoL of people with agoraphobia (as mean score of SF-12) drawn from the community survey database. The control sample was obtained by randomization after blocks. For each person with agoraphobia, a cell selecting all the people without agoraphobia of the same age was carried out, thus four people were selected by randomization from each obtained cell.

The burden in worsening of HR-QoL attributable to agoraphobia was also compared to a similar meaure obtained to other diseases, in previous case-control studies that have adopted the same database as sources of controls.

In people with agoraphobia the number of those who sub- mitted an SF-12 questionnaire score on quality of life below 35 (poor HR-Qol) and above 38 (good HR-Qol) was also calculated; these cutt offs were suggested by the distribution of the score to the scale in the general population. ${ }^{17}$

\section{RESULTS}

The overall lifetime prevalence of agoraphobia was of 35 cases out of 2338 people (1.5\%). There were 26 cases with comorbid panic disorder and 9 cases without comorbid panic disorder.

Table 1 showed lifetime prevalence of agoraphobia by sex and age, the prevalence was $0.9 \%$ in men $2.0 \%$ in women (OR= 2.23; 95\% CI: 1.0-5.2), no differences were found according to age distribution.

The cases of agoraphobia with panic disorder have higher lifetime prevalence than those without panic disorder (1.1\% vs. $0.4 \% \mathrm{OR}=8.3 ; 2.9-24.4$ ) (Table 2 ), with no differences in distribution by gender and age in the subgroups of agoraphobia (with and without panic disorder), with a marginal rise among young people $(\mathrm{OR}=8.0 ; 0.9-73.4)$.

Table 3 showed the association between agoraphobia and other anxiety disorders, major depressive disorder, and posttraumatic stress disorder. Agoraphobia was often comorbid with major depressive disorder ( $\mathrm{OR}=16.2 ; 7.3-35.6)$; panic disorder ( $\mathrm{OR}=87.0 ; 37.3-208.2)$; simple phobia $\mathrm{OR}=7.7$ (2.521.9); social phobia $\mathrm{OR}=59.3$ (12.6-271.3); generalized anxiety disorder $(\mathrm{OR}=12.0 ; 4.5-30.6)$; obsessive-compulsive disorder $(\mathrm{OR}=7.1 ; 2.0-22.5)$; post-traumatic stress disorder $(\mathrm{OR}=$ $9.2 ; 1.4-44.9)$.

The co-morbidity with anxiety disorders, major depression and post-traumatic stress disorder was perfectly superimposable in cases of agoraphobia with or without panic disorder (Table 4).

Table 1. Lifetime prevalence of agoraphobia by gender and age

\begin{tabular}{lccccc}
\hline & $\mathrm{N}(\%)$ & $\chi^{2}(\mathrm{df}=1)$ & $\mathrm{p}$ & $\mathrm{OR}$ & $95 \% \mathrm{CI}$ \\
\hline$<25$ males & $0(0)$ & - & & & \\
$25-44$ & $2(0.5)$ & $0.001^{*}$ & 0.977 & 0.0 & $0-11.7$ \\
$45-64$ & $3(1.0)$ & $0.250^{*}$ & 0.617 & 0.0 & $0-5.2$ \\
$>64$ & $4(2.1)$ & $0.403^{*}$ & 0.235 & 0.0 & $0-2.14$ \\
Total males* & $9(0.9)$ & & & & \\
$<25$ females & $3(2.2)$ & - & & & \\
$25-44$ & $9(2.0)$ & 0.226 & 0.884 & 1.01 & $0.29-3.72$ \\
$45-64$ & $13(2.7)$ & 0.214 & 0.643 & 0.77 & $0.21-2.47$ \\
$>64$ & $1(0.4)$ & 0.242 & 0.875 & 0.91 & $0.22-3.34$ \\
Total females & $26(2.0)$ & 5.520 & 0.033 & 2.24 & $1.0-5.17$ \\
$<45$ vs. $>44$ in $\mathrm{M}+\mathrm{F}$ & 1.3 & 0.734 & 0.392 & 0.74 & $0.4-1.4$ \\
\hline
\end{tabular}

* with Yates's correction, ${ }^{\dagger}$ female vs. males 
The mean score of SF-12 in people with agoraphobia was $35.2 \pm 7.8$, with similar levels of HR-QoL in people with $(\mathrm{n}=$ $26)$ or without panic disorder $(n=9): 35.3 \pm 7.9$ vs. $34.8 \pm 7.3$ [ANOVA: $\mathrm{F}(1 ; 33)=0.0 ; \mathrm{p}=1.00$ ]. As many as 14 out of 35 individuals diagnosed with agoraphobia (40\%) had an SF-12 score higher than or equal to 39, which indicates a good level of HRQoL, while 16 (45.7\%) had an HR-QoL level lower than 35 (poor HR-QoL). Overall, agoraphobia showed an attributable burden comparable to that observed for the other investigated disorders (Table 5).

Table 2. Comparing lifetime prevalence by gender and sex of agoraphobia with panic disorder vs agoraphobia without panic disorder

\begin{tabular}{|c|c|c|c|c|c|c|}
\hline & $\begin{array}{l}\text { Agoraphobia with } \\
\text { panic disorder (\%) }\end{array}$ & $\begin{array}{l}\text { Agoraphobia without } \\
\text { panic disorder (\%) }\end{array}$ & $\chi^{2}(\mathrm{df}=1)$ & $\mathrm{p}$ & OR & $95 \% \mathrm{CI}$ \\
\hline Males & $5(0.5)$ & $4(0.4)$ & $0.294^{*}$ & 0.192 & 0.3 & $0.06-1.5$ \\
\hline Female & $21(1.6)$ & $5(0.4)$ & & & & \\
\hline$<45$ with vs. without & $13(1.2)$ & $1(0.1)$ & $0.097^{*}$ & 0.056 & 8.0 & $0.9-73.4$ \\
\hline$>44$ with vs. without & $13(1.0)$ & $8(0.6)$ & & & & \\
\hline Total (1.5\%) & $26(1.1)$ & $9(0.4)$ & $14.63^{*}$ & $<0.0001$ & 8.3 & $2.9-24.4$ \\
\hline
\end{tabular}

*with Yates's correction

Table 3. Comorbidity between agoraphobia and other disorders

\begin{tabular}{lccccc}
\hline & Comorbid with agoraphobia $(\%)$ & $\chi^{2}(\mathrm{df}=1)$ & $\mathrm{p}$ & OR & $95 \%$ CI \\
\hline Major depressive disorder & $12(34.3)$ & 96.63 & $<0.0001$ & 16.2 & $7.3-35.6$ \\
Panic disorder & $26(74.2)$ & 425.3 & $<0.0001$ & 87.0 & $37.3-208.2$ \\
Simple phobia & $5(14.3)$ & $17.51^{*}$ & $<0.0001$ & 7.7 & $2.5-21.9$ \\
Social phobia & $4(11.4)$ & $86.66^{*}$ & $<0.0001$ & 59.3 & $12.6-271.3$ \\
Generalized anxiety disorder & $7(20.0)$ & 47.3 & $<0.0001$ & 12.0 & $4.5-30.6$ \\
Obsessive-compulsive disorder & $4(11.4)$ & $12.27^{*}$ & $<0.0001$ & 7.1 & $2.0-22.5$ \\
Post-traumatic stress disorder & $2(5.7)$ & $6.23^{*}$ & 0.0013 & 9.2 & $1.4-44.9$ \\
\hline
\end{tabular}

*with Yates's correction

Table 4. Comorbidity in agoraphobia with and without panic disorders

\begin{tabular}{lccccc}
\hline & $\begin{array}{c}\text { Agoraphobia with } \\
\text { panic disorder (\%) }\end{array}$ & $\begin{array}{c}\text { Agoraphobia without } \\
\text { panic disorder (\%) }\end{array}$ & Fisher' p & OR & 95\% CI \\
\hline Major depressive disorder & $10(47.6)$ & $2(22.2)$ & 1.00 & 3.2 & $0.5-19.0$ \\
Simple phobia & $4(10.0)$ & $1(11.1)$ & 1.00 & 1.8 & $0.2-19.9$ \\
Social phobia & $3(14.2)$ & $1(11.1)$ & 1.00 & 1.3 & $0.1-14.9$ \\
Generalized anxiety disorder & $5(23.8)$ & $2(22.2)$ & 1.00 & 1.1 & $0.2-7.1$ \\
Obsessive-compulsive disorder & $3(14.2)$ & $1(11.1)$ & 1.00 & 1.3 & $0.1-14.9$ \\
Post-traumatic stress disorder & $2(5.7)$ & $0(0)$ & 1.00 & - & - \\
\hline
\end{tabular}

Table 5. Attributable Burden in worsening Quality of Life due to Agoraphobia and comparison with other disorders

\begin{tabular}{lccc}
\hline & SF-12 $($ mean \pm SD $)$ & Attributable burden due to the disorder & ANOVA* \\
\hline Agoraphobia & $35.2 \pm 7.8$ & $3.4 \pm 3.6(\mathrm{~N}=35)$ & $\mathrm{F}(1 ; 70)=6.6 ; \mathrm{p}=0.012$ \\
Major depressive disorder & $33.8 \pm 9.2$ & $5.6 \pm 3.6(\mathrm{~N}=37)$ & $\mathrm{F}(1 ; 156)=0.72 ; \mathrm{p}=0.396$ \\
Panic disorder & $35.5 \pm 4.6$ & $2.9 \pm 0.9(\mathrm{~N}=123)$ & $\mathrm{F}(1 ; 87)=2.48 ; \mathrm{p}=0.119$ \\
Simple phobia & $35.8 \pm 6.1$ & $2.5 \pm 2.4(\mathrm{~N}=54)$ & $\mathrm{F}(1 ; 121)=0.21 ; \mathrm{p}=0.646$ \\
Obsessive-compulsive disorder & $35.4 \pm 6.9$ & $2.9 \pm 6.0(\mathrm{~N}=88)$ & $\mathrm{F}(1 ; 59)=0.47 ; \mathrm{p}=0.495$ \\
Post-traumatic stress disorder & $36.3 \pm 6.1$ & $3.9 \pm 1.0(\mathrm{~N}=26)$ &
\end{tabular}

Attributable Burden=Quality of Life in a matching control group without Agoraphobia (matching controls 1/4 from the community). *comparison with agoraphobia without panic disorder. SD: standard deviation, N: number (i.e., sample size), SF-12: 12-item Short-Form Health Survey, ANOVA: analysis of variance 


\section{DISCUSSION}

The lifetime prevalence of agoraphobia found by our study is in the range of the estimates found by studies that used DSMIV criteria for diagnosis or that have recalculated rates with DSM-5. The World Health Survey (WHS) found lifetime prevalence of agoraphobia of $1.4 \%$ according to DSM-IV criteria and $1.5 \%$ according with those of DSM-5. The National Epidemiologic Survey on Alcohol and Related Conditions (NESARC) had found in the US a lifetime prevalence of $1.3 \%$ (as a sum of panic disorder with agoraphobia and agoraphobia without panic disorder).$^{18}$ In the same year and still in the US, the National Comorbidity Survey Replication (NCS-R) had found a lifetime prevalence of panic disorder with agoraphobia of $1.1 \%$ and agoraphobia with panic disorder $0.8 \%$ according DSM-IV. ${ }^{19}$

The prevalence of agoraphobia without panic disorder in the present study is in the range of previous studies conducted with the DSM-5: from $0.2 \%$ of NESARC to $1.0 \%$ of WHS. It is also not far from the results of a study carried out in Derry, North Irleand, ${ }^{20}$ which used a two phases design and found a lifetime prevalence of $0.7 \%$ of ICD-10 agoraphobia without panic disorder. As far as the specific prevalence of agoraphobia without panic disorder is concerned, our studies seem to be quite distant from almost all studies conducted using DSM-IV as a criterion and highly structured tools for diagnosis conducted by lay interviewers. ${ }^{21}$ However, in the European Study on the Epidemiology of Mental Disorders (ESEMeD) ther pooled data from France, Belgium, Spain, The Netherland and Italy showed a liferime prevalence of agoraphobia without panic disorder of $0.9 \% .^{22}$

Other studies found a higher prevalence than in the present study: Munchen Region, Germany (2.6\%); $;{ }^{23}$ Finland (0.7\%); ${ }^{24}$ Dresden, Germany (1.8\%); ${ }^{25}$ The Netherland (1.6\%); $;^{26}$ Oslo Norway (3.1\%); ${ }^{27}$ Germany (2\%). ${ }^{28}$ It should be noted, however, that the only study that used trained clinical interviewers (in Sesto Fiorentino, Italy), even with structured interviews and using DSM-IV as a criterion, lifetime prevalence figures were much lower than in the others DSM-IV surveys $(0.4 \%$ versus, on average, $2.0 \%$ ) and much closer to ours. ${ }^{29}$ In the WHS database, the comparison between the diagnoses of agoraphobia without panic disorder carried out applying DSM-IV and DSM-5 criteria indicated that these two systems tend to identify different conditions under the same diagnosis. ${ }^{4}$ Conversely, the diagnoses that are done according to the criteria of the ICD-10 are closer to the ones that are based on the criteria of the DSM-5. ${ }^{4}$ It should be borne in mind that the WHS study, lay interviewers applied a highly structured interview while in the present study clinicians used semi-structured interviews. It is therefore possible that the more clinically oriented method of this study has allowed a more accurate identifi- cation of even the light forms of panic disorder (thus decreasing the quote of agoraphobia without panic disorder). In the past, the debate on the reproducibility of the diagnoses conducted with the semi-structured interviews was in fact the subject of a heated debate, especially regarding mood disorders, with irreconciliable point of views. ${ }^{30,31}$

The two subgroups of agoraphobia with and without panic disorder found in the present study show a very similar profile in terms of age and gender distribution, comorbidity with anxiety disorders, post-traumatic stress disorder, and major depressive disorder, as well as of the level of impairment of quality of life. These findings support the notion that agoraphobia is a homogeneous group and not the confluence of two separate conditions.

As far as the level of impaiment due to agoraphobia is concerned, the result can be considered partly unexpected. Agoraphobia is often thought to be a disabling disorder. ${ }^{32}$ However, in this study agoraphobia did not reach the HR-QoL impairment level of the major depressive disorder, and its HR-QoL impairment was similar to the one observed for panic disorder, obsessive compulsive disorder, post-traumatic stress disorder, and specific phobia. In recent studies, the impact on HRQoL of major depressive disorder was found to be similar to the one produced by severe hematological cancers, ${ }^{33}$ and posttraumatic stress disorder was found to impair HR-QoL more than panic disorder. ${ }^{34}$ Moreover, separate investigations have shown that the impaiment of quality of life attributable to the comorbidity with simple phobia depends on conditions in comorbidity and not on the disturbance itself. ${ }^{35}$ The findings are consistent with other studies that had seen the co-morbid agoraphobic component affecting the quality of life in a measure not inconsistent with other anxiety disorders. ${ }^{36,37}$ Similarly, the impact on quality of life of obsessive-compulsive disorder was found to be influenced by the co-morbidity with bipolar spectrum disorders. ${ }^{38}$

However, the attributable burden of agoraphobia is nonnegligible. When compared to the attributable burden of other chronic and disabling conditions in studies that applied the same methodology of this study, the attributable burden of agoraphobia resulted higher than the attributable found in celiac disease, ${ }^{39}$ lower than in multiple sclerosis ${ }^{40}$ or in fibromyalgia ${ }^{41}$ but comparable to the one observed for Wilson disease and eating disorders. ${ }^{42,43}$

Severe role impaiment was reported in WHS in arond $1 / 3$ of people diagnosed with agoraphobia. This seems to confirm that the share of people in the general population who receives a diagnosis of agoraphobia often presents severe impaiment (WHS) or a strong impairment of quality of life, but this does not apply to all people with agoraphobia equally. The percentage of people with strong impairment of quality of life identi- 
fied by our study on the total of people with ICD-10 agoraphobia (40\%), seems much closer to the percentage of people with DSM-5 agoraphobia identified by WHS as suffering from a strong impairment (43\%), which is a higher percentage of severe impairment among people diagnosed with agoraphobia according to the criteria of the DSM-IV (30\%). It should be noted that in this study women reported a higher prevalence of agoraphobia than men. Past studies found that women are more likely than men to stay at home to avoid agoraphobic situations and are also more likely to look for a companion to going outside. ${ }^{44}$ This may limit their capacity to optimally functioning and may have contributed to the relatively high percentage of participants with a strong impairment of quality of life in people that were diagnosed with ICD-10 agoraphobia in this study (40\%).

Several limitations have to be acknowledged. The study was designed to investigate the prevalence of people diagnosed with the bipolar spectrum, who were estimated to be $4 \%$, but agoraphobia has lower lifetime prevalence. Thus, the frequency of agoraphobia in the study was small, affecting the power to precisely estimate co-morbidity and associations among different disorders. Another limitation is that our study was conducted with a different methodology from most of the comparison epidemiological studies, with the use of clinical interviewers and with the ICD-10 diagnosis, which is not frequent in epidemiological studies.

The study seems to confirm a homogeneous profile in agoraphobia dependent on comorbidity of panic disorder; this profile concerns the associated conditions such as gender, age, anxiety and disorders in comorbidity and the impairment produced in quality of life. The disorder presents itself as a condition capable of producing a serious impairment of the quality of life but not in all the people affected by it.

\section{Acknowledgments}

This study was supported by a grant of AIFA (Agenzia Italiana del Farmaco) Number FARM54S73S, approved in 2005.

\section{Conflicts of Interest}

The authors have no potential conflicts of interest to disclose.

\section{Author Contributions}

Conceptualization: Mauro Giovanni Carta, Matteo Balestrieri, Liliana Dell'Osso, Rita Roncone, Carlo Faravelli, Antonio Preti. Data curation: Mauro Giovanni Carta, Matteo Balestrieri, Liliana Dell'Osso, Rita Roncone, Carlo Faravelli, Ferdinando Romano, Filippo Caraci, Guido di Sciascio, Filippo Drago, Mario Musu, Gabriele Finco, Maria Carolina Hardoy. Formal analysis: Mauro Giovanni Carta, Maria Francesca Moro, Maria Carolina Hardoy. Funding acquisition: Mauro Giovanni Carta, Matteo Balestrieri, Liliana Dell'Osso, Rita Roncone, Carlo Faravelli, Filippo Drago, Gabriele Finco. Investigation: Mauro Giovanni Carta, Matteo Balestrieri, Liliana Dell'Osso, Rita Roncone, Carlo Faravelli, Martina Piras, Giulia Cossu, Elisa Pintus, Mirra Pintus, Goce Kalcev, Federico Cabras. Methodology: Mauro Giovanni Carta, Antonio Egidio Nardi, Antonio Preti. Proj- ect administration: all authors. Resources: all authors. Software: all authors. Supervision: all authors. Validation: all authors. Visualization: all authors. Writing—original draft: all authors. Writing—review \& editing: all authors.

\section{ORCID iDs}

Antonio Preti

Martina Piras

Giulia Cossu

Elisa Pintus

Mirra Pintus

Goce Kalcev

Federico Cabras

Maria Francesca Moro

Ferdinando Romano

Matteo Balestrieri

Filippo Caraci

Liliana Dell'Osso

Guido Di Sciascio

Filippo Drago

Maria Carolina Hardoy

Rita Roncone

Carlo Faravelli

Mario Musu

Gabriele Finco

Antonio Egidio Nardi

Mauro Giovanni Carta

\section{REFERENCES}

1. American Psychiatric Association. Diagnostic and Statistical Manual of Mental Disorders (4th Ed., Text Revision). Washington, DC: American Psychiatric Press; 2000.

2. American Psychiatric Association. Diagnostic and Statistical Manual of Mental Disorders (5th ed). Washington, DC: American Psychiatric Press; 2013.

3. Catarozoli C, Mishan L, Schild J, Bennett SM. Panic Disorder and Agoraphobia. In: Compton SN, Villabø MA, Kristensen H, Editors. Pediatric Anxiety Disorders. London: Academic Press, 2019, p.177-200.

4. Roest AM, de Vries YA, Lim CCW, Wittchen HU, Stein DJ, Adamowski T, et al. A comparison of DSM-5 and DSM-IV agoraphobia in the World Mental Health Surveys. Depress Anxiety 2019;36:499-510.

5. Carpenter JK, Andrews LA, Witcraft SM, Powers MB, Smits JAJ, Hofmann SG. Cognitive behavioral therapy for anxiety and related disorders: a meta-analysis of randomized placebo-controlled trials. Depress Anxiety 2018;35:502-514.

6. Plag J, Petzold MB, Gechter J, Liebscher C, Ströhle A. Patients' characteristics and their influence on course of fear during agoraphobic symptom provocation: may SS(N)RI treatment compensate unfavorable individual preconditions? Nord J Psychiatry 2018;72:325-335.

7. Asmundson GJ, Taylor S, Smits JA. Panic disorder and agoraphobia: an overview and commentary on DSM-5 changes. Depress Anxiety 2014;31:480-486.

8. Lu J, Huang YQ, Liu ZR, Cao XL. Validity of Chinese version of the Composite International Diagnostic Interview-3.0 in psychiatric settings. Chin Med J (Engl) 2015;128:2462-2466.

9. Kimerling R, Serpi T, Weathers F, Kilbourne AM, Kang H, Collins JF, et al. Diagnostic accuracy of the Composite International Diagnostic Interview (CIDI 3.0) PTSD module among female Vietnam-era veterans. J Trauma Stress 2014;27:160-167.

10. World Health Organization. ICD-10: International Statistical Classification of Diseases and Related Health Problems: Tenth Revision, 2nd Ed. Geneva: World Health Organization; 2004. https://apps.who.int/ iris/handle/10665/42980.

11. World Medical Association. World Medical Association Declaration of Helsinki: ethical principles for medical research involving human sub- 
jects. JAMA 2013;310:2191-2194.

12. Carta MG, Aguglia E, Bocchetta A, Balestrieri M, Caraci F, Casacchia $\mathrm{M}$, et al. The use of antidepressant drugs and the lifetime prevalence of major depressive disorders in Italy. Clin Pract Epidemiol Ment Health 2010;6:94-100.

13. First M, Spitzer R, Gibbon M, Williams J. Structured Clinical Interview for DSM-IV Axis I Disorders, Research Version, Non-Patient Edition (SCID-I/NP). New York: Biometrics Research, New York State Psychiatric Institute; 1997.

14. Ware J Jr, Kosinski M, Keller SD. A 12-Item Short-Form Health Survey: construction of scales and preliminary tests of reliability and validity. Med Care 1996;34:220-233.

15. Mantovani G, Astara G, Lampis B, Bianchi A, Curreli L, Orrù W, et al. Evaluation by multidimensional instruments of heath-related quality of life of elderly cancer patients undergoing three different "psychosocial" treatment approaches. A randomized clinical trial. Support Care Cancer 1996;4:129-140.

16. Miettinen O, Nurminen M. Comparative analysis of two rates. Stat Med 1985;4:213-226.

17. Carta MG, Aguglia E, Caraci F, Dell'Osso L, Di Sciascio G, Drago F, et al. Quality of life_and urban / rural living: preliminary results of a community survey in Italy. Clin Pract Epidemiol Ment Health 2012;8: 169-174.

18. Grant BF, Hasin DS, Stinson FS, Dawson DA, Goldstein RB, Smith S, et al. The epidemiology of DSM-IV panic disorder and agoraphobia in the United States: results from the National Epidemiologic Survey on Alcohol and Related Conditions. J Clin Psychiatry 2006;67:363-374.

19. Kessler RC, Chiu WT, Jin R, Ruscio AM, Shear K, Walters EE. The epidemiology of panic attacks, panic disorder, and agoraphobia in the National Comorbidity Survey Replication. Arch Gen Psychiatry 2006;63: 415-424.

20. McConnell P, Bebbington P, McClelland R, Gillespie K, Houghton S. Prevalence of psychiatric disorder and the need for psychiatric care in Northern Ireland. Population study in the District of Derry. Br J Psychiatry 2002;181:214-219.

21. Goodwin RD, Faravelli C, Rosi S, Cosci F, Truglia E, de Graaf R, et al. The epidemiology of panic disorder and agoraphobia in Europe. Eur Neuropsychopharmacol 2005;15:435-443.

22. Alonso J, Angermeyer MC, Bernert S, Bruffaerts R, Brugha TS, Bryson $\mathrm{H}$, et al. Prevalence of mental disorders in Europe: results from the European Study of the Epidemiology of Mental Disorders (ESEMeD) project. Acta Psychiatr Scand Suppl 2004;(420):21-27.

23. Wittchen HU. Natural Course and Spontaneous Remissions of Untreated Anxiety Disorders-Results of the Munich Follow-up Study (MFS). In: Hand I, Wittchen HU, Editors. Panic and Phobias: 2. Treatments and Variables Affecting Course and Outcome. Berlin: Springer, 1988, p.3-17.

24. Pirkola SP, Isometsä E, Suvisaari J, Aro H, Joukamaa M, Poikolainen K, et al. DSM-IV mood-, anxiety- and alcohol use disorders and their comorbidity in the Finnish general population--results from the Health 2000 Study. Soc Psychiatry Psychiatr Epidemiol 2005;40:1-10.

25. Becker ES, Türke V, Neumer S, Soeder U, Krause P, Margraf J. Incidence and Prevalence Rates of Mental Disorders in a Community Sample of Young Women: Results of the "Dresden study". In: Heeb-Erler G, Manz R, Kirch W, Editors. Public Health Research and Practice: Report of the Public Health Research Association. Saxony Regensburg: Roderer, 2000, p.259-292.

26. Bijl RV, Ravelli A, van Zessen G. Prevalence of psychiatric disorder in the general population: results of The Netherlands Mental Health Survey and Incidence Study (NEMESIS). Soc Psychiatry Psychiatr Epidemiol 1998;33:587-595.

27. Kringlen E, Torgersen S, Cramer V. A Norwegian psychiatric epidemi- ological study. Am J Psychiatry 2001;158:1091-1098.

28. Jacobi F, Wittchen HU, Holting C, Höfler M, Pfister H, Müller N, et al. Prevalence, co-morbidity and correlates of mental disorders in the general population: results from the German Health Interview and Examination Survey (GHS). Psychol Med 2004;34:597-611.

29. Faravelli C, Abrardi L, Bartolozzi D, Cecchi C, Cosci F, D’Adamo D, et al. The Sesto Fiorentino study: point and one-year prevalences of psychiatric disorders in an Italian community sample using clinical interviewers. Psychother Psychosom 2004;73:226-234.

30. Kessler RC, Akiskal HS, Angst J, Guyer M, Hirschfeld RM, Merikangas KR, et al. Validity of the assessment of bipolar spectrum disorders in the WHO CIDI 3.0. J Affect Disord 2006;96:259-269.

31. Carta MG, Angst J. Screening for bipolar disorders: a public health issue. J Affect Disord 2016;205:139-143.

32. Quilty LC, Van Ameringen M, Mancini C, Oakman J, Farvolden P. Quality of life and the anxiety disorders. J Anxiety Disord 2003;17: 405-426.

33. La Nasa G, Caocci G, Morelli E, Massa E, Farci A, Deiana L, et al. Health related quality of life in patients with onco-hematological diseases. Clin Pract Epidemiol Ment Health 2020;16:174-179.

34. Sancassiani F, Carmassi C, Romano F, Balestrieri M, Caraci F, Di Sciascio G, et al. Impairment of quality of life associated with lifetime diagnosis of post-traumatic stress disorder in women - a national survey in Italy. Clin Pract Epidemiol Ment Health 2019;15:38-43.

35. Sancassiani F, Romano F, Balestrieri M, Caraci F, Di Sciascio G, Drago F, et al. The prevalence of specific phobia by age in an Italian nationwide survey: how much does it affect the quality of life? Clin Pract Epidemiol Ment Health 2019;15:30-37.

36. Holubova M, Prasko J, Ociskova M, Kantor K, Vanek J, Slepecky M, et al. Quality of life, self-stigma, and coping strategies in patients with neurotic spectrum disorders: a cross-sectional study. Psychol Res Behav Manag 2019;12:81-95.

37. Alonso J, Angermeyer MC, Bernert S, Bruffaerts R, Brugha TS, Bryson $\mathrm{H}$, et al. Disability and quality of life impact of mental disorders in $\mathrm{Eu}-$ rope: results from the European Study of the Epidemiology of Mental Disorders (ESEMeD) project. Acta Psychiatr Scand Suppl 2004;(420): 38-46.

38. Carta MG, Fineberg N, Moro MF, Preti A, Romano F, Balestrieri M, et al. The burden of comorbidity between bipolar spectrum and obsessive-compulsive disorder in an Italian community survey. Front Psychiatry 2020;11:188.

39. Carta MG, Conti A, Lecca F, Sancassiani F, Cossu G, Carruxi R, et al. The burden of depressive and bipolar disorders in celiac disease. Clin Pract Epidemiol Ment Health 2015;11:180-185.

40. Carta MG, Moro MF, Lorefice L, Picardi A, Trincas G, Fenu G, et al. Multiple sclerosis and bipolar disorders: the burden of comorbidity and its consequences on quality of life. J Affect Disord 2014;167:192197.

41. Carta MG, Moro MF, Pinna FL, Testa G, Cacace E, Ruggiero V, et al. The impact of fibromyalgia syndrome and the role of comorbidity with mood and post-traumatic stress disorder in worsening the quality of life. Int J Soc Psychiatry 2018;64:647-655.

42. Carta MG, Sorbello O, Moro MF, Bhat KM, Demelia E, Serra A, et al. Bipolar disorders and Wilson's disease. BMC Psychiatry 2012;12:52.

43. Carta MG, Preti A, Moro MF, Aguglia E, Balestrieri M, Caraci F, et al. Eating disorders as a public health issue: prevalence and attributable impairment of quality of life in an Italian community sample. Int Rev Psychiatry 2014;26:486-492.

44. Starcevic V, Djordjevic A, Latas M, Bogojevic G. Characteristics of agoraphobia in women and men with panic disorder with agoraphobia. Depress Anxiety 1998;8:8-13. 